\title{
EDITORIAL
}

\section{Cambios en la Revista}

La Revista Chilena de Cirugía ha sido el órgano de difusión de la actividad quirúrgica de los cirujanos chilenos durante más de medio siglo.

Durante todo este largo tiempo los especialistas han publicado en sus páginas artículos de investigación básica y clínica y otros documentos que han buscado difundir y actualizar el conocimiento médico en general y el quirúrgico en particular.

En este caso la Sociedad de Cirujanos de Chile actúa como Editorial, siendo propietaria de los derechos y responsable legal de sus contenidos. De esta manera esta sociedad científica cumple con uno de sus objetivos intrínsecos, comunicar la ciencia.

La función editorial es central. El editor es quién recibe las colaboraciones y, una vez corroborado que cumplen con las normas de la revista, organiza la revisión por pares y toma las decisiones de aceptación. Además el editor debe en ocasiones corregir los "manuscritos", lo que puede implicar hacer cambios importantes en el texto.

En el mundo de las publicaciones científicas actual, se considera fundamental la evaluación o revisión por pares de los artículos recibidos. Deben ser pares con conocimiento del tema a evaluar, y en lo posible independientes del comité editorial.

Aquí se introduce una importante variación respecto a lo tradicional en nuestra revista, en la que lo usual era precisamente lo contrario, es decir que los revisores eran justamente aquellos pertenecientes a dicho comité; se considera que la evaluación por parte del universo invisible al que pertenece el autor mejora la calidad del material publicado. Sin embargo, los evaluadores deben aconsejar y no decidir, quiénes deciden que se publica o que se rechaza son el editor o el consejo de editores, los que deben estar capacitados para identificar la importancia y calidad de los artículos y de las modificaciones propuestas.

Internet es muy importante para la publicación de revistas, las que pueden tener una versión impresa y otra electrónica idénticas, versiones diferentes, o solo una versión electrónica. Consideramos en el momento actual que la Revista en el formato de papel que conocemos debe permanecer. Sin embargo también consideramos importante que además tenga una amplia difusión en las bases electrónicas, de hecho se la puede encontrar en LILACS como resumen, y a texto completo en la pagina web de la sociedad y en la base de revistas electrónicas de las bibliotecas de la Universidad de Chile (www.al-dia.cl). Pero nuestro interés va mas lejos y estamos muy cerca de ingresar a ScieLo, en el concierto de Latinoamérica, y en su momento intentaremos el ingreso a Medline.

Lo anterior requiere de cambios profundos en los conceptos editoriales, en la calidad de los artículos publicados, el reforzamiento de la evaluación por pares y un adecuado financiamiento del personal indispensable para una publicación de este significado. Para ello se está trabajando en una tarea que requiere de la estrecha cooperación con el Directorio y con la comunidad médica.

Dr. Julio YARMUCH G. Editor Jefe

Revista Chilena de Cirugía 